
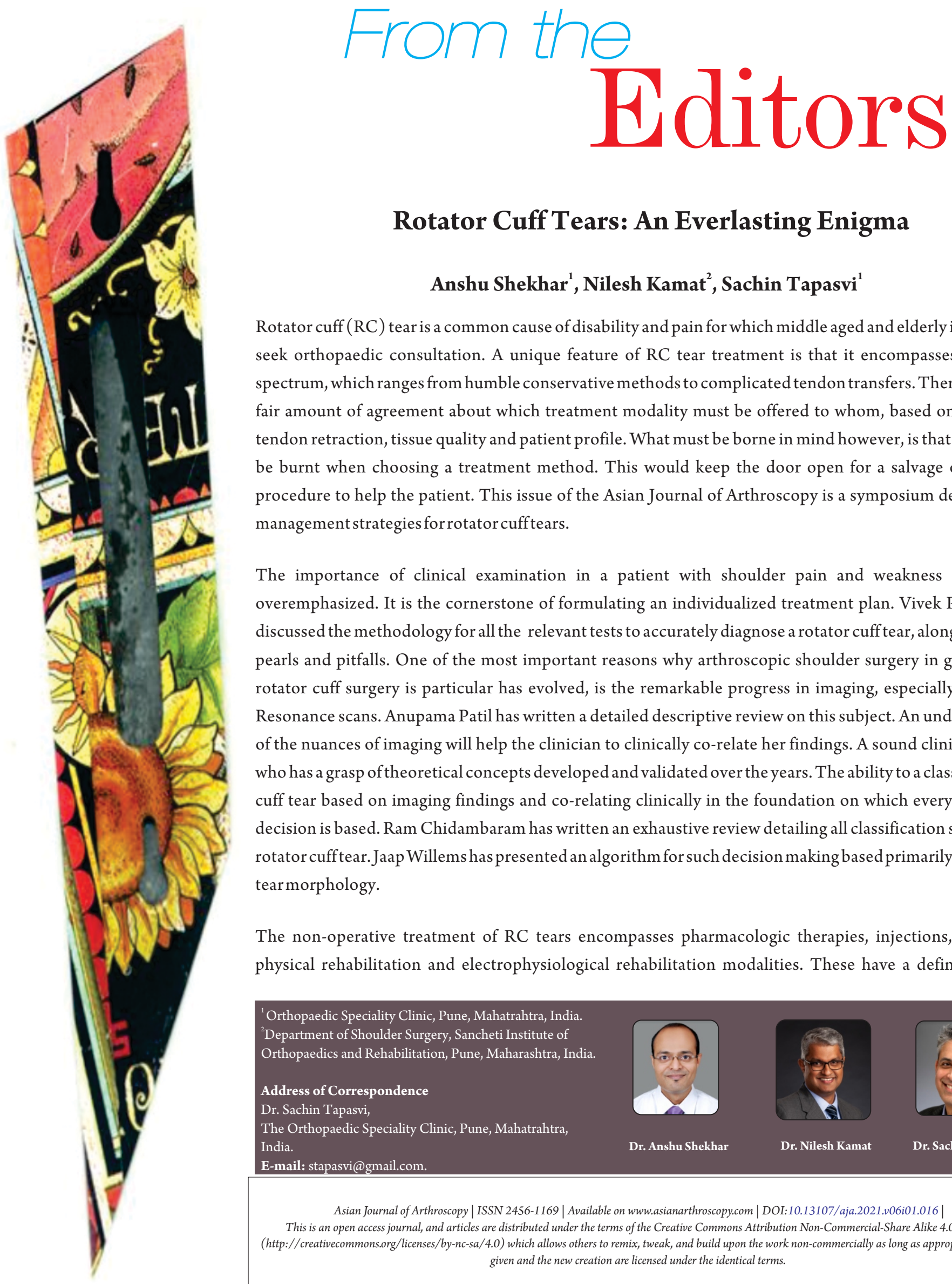

\title{
Rotator Cuff Tears: An Everlasting Enigma
}

\section{Anshu Shekhar ${ }^{1}$, Nilesh Kamat ${ }^{2}$, Sachin Tapasvi ${ }^{1}$}

Rotator cuff (RC) tear is a common cause of disability and pain for which middle aged and elderly individuals seek orthopaedic consultation. A unique feature of RC tear treatment is that it encompasses an entire spectrum, which ranges from humble conservative methods to complicated tendon transfers. There is a now a fair amount of agreement about which treatment modality must be offered to whom, based on tear type, tendon retraction, tissue quality and patient profile. What must be borne in mind however, is that no bridges be burnt when choosing a treatment method. This would keep the door open for a salvage or revision procedure to help the patient. This issue of the Asian Journal of Arthroscopy is a symposium dedicated to management strategies for rotator cufftears.

The importance of clinical examination in a patient with shoulder pain and weakness cannot be overemphasized. It is the cornerstone of formulating an individualized treatment plan. Vivek Pandey has discussed the methodology for all the relevant tests to accurately diagnose a rotator cuff tear, along with their pearls and pitfalls. One of the most important reasons why arthroscopic shoulder surgery in general and rotator cuff surgery is particular has evolved, is the remarkable progress in imaging, especially Magnetic Resonance scans. Anupama Patil has written a detailed descriptive review on this subject. An understanding of the nuances of imaging will help the clinician to clinically co-relate her findings. A sound clinician is one who has a grasp of theoretical concepts developed and validated over the years. The ability to a classify rotator cuff tear based on imaging findings and co-relating clinically in the foundation on which every treatment decision is based. Ram Chidambaram has written an exhaustive review detailing all classification systems for rotator cufftear.Jaap Willems has presented an algorithm for such decision making based primarily on age and tear morphology.

The non-operative treatment of RC tears encompasses pharmacologic therapies, injections, biologics, physical rehabilitation and electrophysiological rehabilitation modalities. These have a definite role in

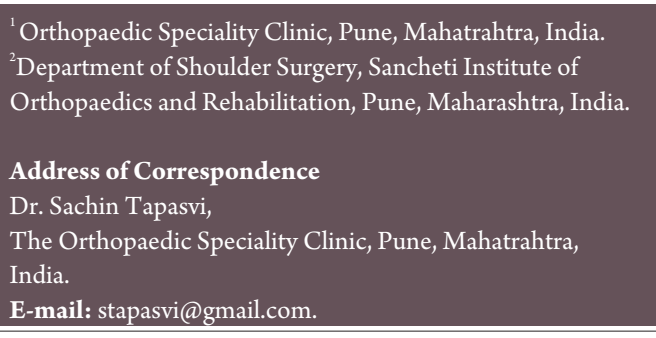

Asian Journal of Arthroscopy | ISSN 2456-1169 | Available on www.asianarthroscopy.com | DOI:10.13107/aja.2021.v06i01.016 | This is an open access journal, and articles are distributed under the terms of the Creative Commons Attribution Non-Commercial-Share Alike 4.0 License (http://creativecommons.org/licenses/by-nc-sa/4.0) which allows others to remix, tweak, and build upon the work non-commercially as long as appropriate credit is given and the new creation are licensed under the identical terms. 
management of RC tears and Denny Lie has performed a systematic review of randomized current trials to present the current evidence for the same. Arthroscopic rotator cuff repair for degenerative tears is now a standard of care in those who fail a trial of non-operative treatment. It has demonstrated proven health and economic benefits in the mid-term $[1,2]$. A lacuna is current literature is the absence of large randomized controlled trial with long-term results which would settle the debate conclusively. The repair technique has also travelled a full circle with new vigor seen for trans-osseous repairs after having seen the fallacies of anchor-based repairs in the last couple of decades. The issue of subacromial decompression is another elephant in the room on which everybody seems to agree to disagree. SAD does have a definite place in RC repair surgery, considering its potential biological and mechanical benefits. However, what constitutes a 'decompression' and how much of an impact does it really have on a multifactorial phenomenon like rotator cuff healing is largely unknown. Amol Tambe has written an exhaustive review on this subject which will help the readers tailor their approach approach to this enigma.

The aim of this issue is to provide the reader with information and knowledge on rotator cuff tears which can then be used to guide patient management. We hope that the wealth of knowledge shared by our authors will enrich the readers and help them in making better decisions when treating their patients.

\section{References}

1. Piper CC, Hughes AJ, Ma Y, Wang H, Neviaser AS. Operative versus nonoperative treatment for the management of full-thickness rotator cufftears: a systematic review and meta-analysis. J Shoulder Elbow Surg. 2018 Mar;27(3):572-576.
2. Mather RC 3rd, Koenig L, Acevedo D, Dall TM, Gallo P, Romeo A, Tongue J, Williams $G J$ r. The societal and economic value of rotator cuff repair. J Bone JointSurg Am.2013 Nov 20;95(22):1993-2000.

\section{Conflict of Interest: NIL} Source of Support: NIL

\section{How to Cite this Article}

Shekhar A, Kamat N, Tapasvi S | Rotator Cuff Tears: An Everlasting Enigma | Asian Journal of Arthroscopy | January-June 2021; 6(1):01-02. 